\title{
Atomically dispersed Rh active sites on oxide supports with controlled acidity for gas-phase halide-free methanol carbonylation to acetic acid
}

Ji Qi, Phillip Christopher

Department of Chemical Engineering, University of California, Santa Barbara, Santa Barbara, California 93117, United States.

*Corresponding Author Email: pchristopher@ucsb.edu

Figure S1: Methanol consumption rates as function of superficial velocity

Figure S2: Acetic acid production rate during methanol carbonylation on $\gamma-\mathrm{Al}_{2} \mathrm{O}_{3}, 3 \mathrm{wt} \% \mathrm{Rh} / \gamma$ $\mathrm{Al}_{2} \mathrm{O}_{3}$ and $0.2 \mathrm{wt} \% \mathrm{Rh} / \gamma-\mathrm{Al}_{2} \mathrm{O}_{3}$ 


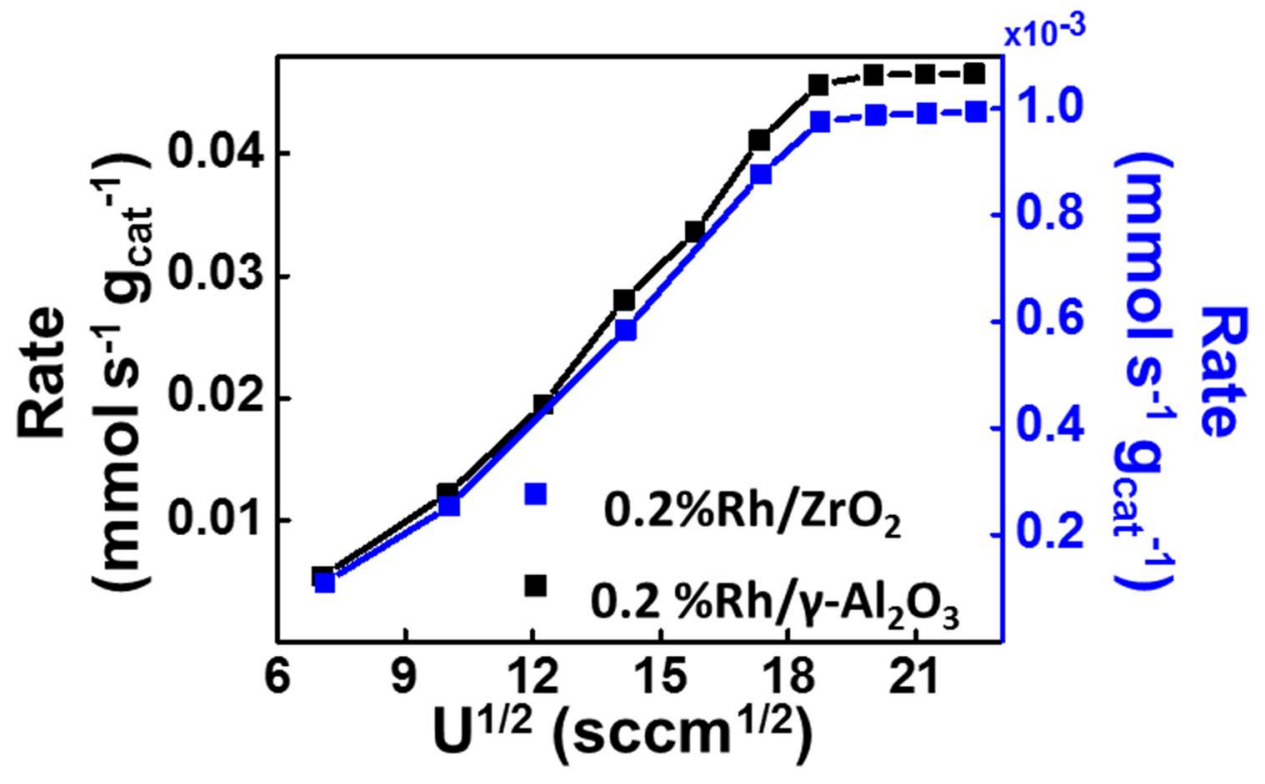

Figure S1. Methanol consumption rates at $300 \mathrm{C}$ and $33 \mathrm{mbar}$ methanol and $\mathrm{CO}$ as a function of the square root of the superficial velocity. $0.2 \mathrm{wt} \% \mathrm{Rh} / \gamma-\mathrm{Al}_{2} \mathrm{O}_{3}$ and $0.2 \mathrm{wt} \% \mathrm{Rh} / \mathrm{ZrO}_{2}$ showed rates independent on the superficial velocity starting from $350 \mathrm{~cm}^{3} \mathrm{~min}^{-1}$. A superficial velocity of $350 \mathrm{~cm}^{3} \mathrm{~min}^{-1}\left(140 \mathrm{~cm}^{3} \mathrm{~min}^{-1}\right.$ of Ar to purge methanol and $210 \mathrm{~cm}^{3} \mathrm{~min}^{-1}$ of $10 \% \mathrm{CO} / 90 \% \mathrm{Ar}$ ) was chosen for all kinetic experiments.

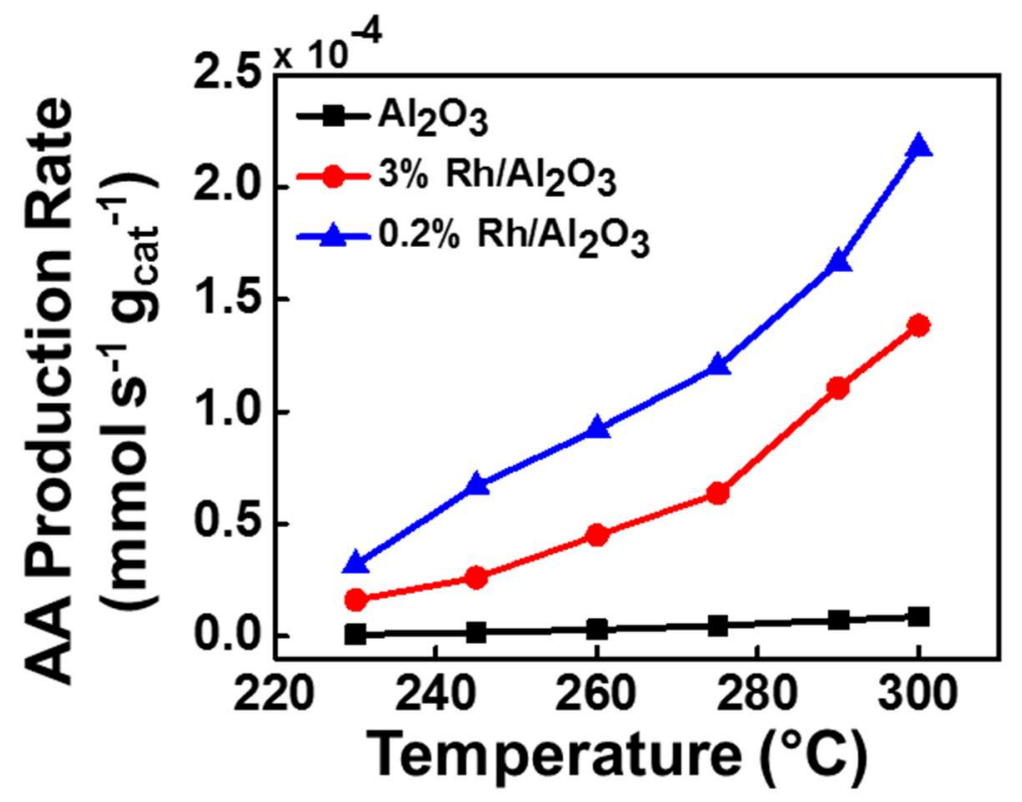

Figure S2. Production rate of acetic acid dur methanol carbonylation at 33 mbar methanol and 33 mbar $\mathrm{CO}$ as a function of temperature on $\gamma-\mathrm{Al}_{2} \mathrm{O}_{3}, 3 \mathrm{wt} \% \mathrm{Rh} / \gamma-\mathrm{Al}_{2} \mathrm{O}_{3}$ and $0.2 \mathrm{wt} \% \mathrm{Rh} / \gamma-\mathrm{Al}_{2} \mathrm{O}_{3}$. Before reactivity experiments, catalysts were oxidized at $350{ }^{\circ} \mathrm{C}$ for 1 hour. 